\title{
Editors' Message \\ The value of simple equilibrium approximations for analysing pumping test data
}

\author{
Bruce D.R. Misstear, Associate Editor
}

The aim of this Editors' Message is to highlight the merits of simple equilibrium formulae for analysing pumping test data. It is not the intention to argue that equilibrium approaches should replace the standard non-equilibrium methods where the latter can be applied properly. However, the reality is that good test data are unavailable for the vast majority of the world's wells, and even where time-drawdown data are available, the non-equilibrium methods involving curve-matching or fitting straight lines are often misapplied, with little understanding of the inherent assumptions. Therefore, equilibrium approximations are indeed useful (1) as an initial estimate of transmissivity (T) in the absence of good test data, and (2) for comparison with, and therefore checking on, the results obtained from non-equilibrium analyses even where there are good time-drawdown data. Regarding (2), it may be the case that the equilibrium $\mathrm{T}$ value can be discounted because of leaky conditions, recharge boundaries, or whatever, but at least the process of comparing the results with the non-equilibrium analysis will encourage the hydrogeologist to think about these issues. It is possible that the wide availability of software for interpreting pumping-test data, enabling automatic fitting of straight lines or matching of type curves, discourages some hydrogeologists from giving proper thought to the analysis.

A large number of analytical methods are available for determining aquifer properties from pumping-test data. Different methods have been developed to cope with a wide variety of well and aquifer situations, ranging from simple homogeneous and isotropic aquifers to more complex situations involving anisotropy, barrier boundaries, leaky aquifers, partial well penetration, and so forth. The application of these analytical methods requires both good test data and a good understanding of the assumptions inherent in the methods themselves. In practice, good test data (involving step- and constant-rate tests,

Published online: 9 March 2001

(C) Springer-Verlag 2001

B.D.R. Misstear (

Department of Civil, Structural and Environmental Engineering, Trinity College, Dublin 2, Ireland

e-mail: bmisster@tcd.ie

Fax: +353-1-6773072 with water-level measurements in both abstraction and observation wells) are not found as often as hydrogeologists would wish. For the majority of private wells, test data (if any) may be restricted to short-term specificcapacity values. There may also be a lack of proper pumping-test data at public-water-supply groundwater sources; for example, in cases where the wells have been operating more or less continuously for many years, and where it is not practical to disconnect them from the supply system in order to carry out extended pumping tests under controlled conditions (Misstear and Beeson 2000).

Even where good test data are available there is a tendency among some practising hydrogeologists to adopt a prescriptive approach to the analysis, whereby standard methods such as those of Theis (1935) and Jacob (Cooper and Jacob 1946) are applied to time-drawdown data with little or no regard to the assumptions that underlie these formulae. Thus, in a Jacob analysis, it is not uncommon to encounter a straight line drawn as a best fit through a semi-log data plot that is clearly non-linear, with no discussion of the reasons for the variance between theory and the conditions at the site under investigation. Such an approach can obviously lead to large errors in estimates of aquifer properties. Again, it is not uncommon to see tabulated pumping test results in which the specific capacities of the wells exceed the interpreted transmissivities - with the clear implication that the wells are more productive than the aquifers!

Simple equilibrium approximation formulae can be used to provide an initial estimate of aquifer transmissivity in the many situations where only limited timedrawdown data are available. In cases where there are good test data, the equilibrium approximations can also be useful as a check on the $\mathrm{T}$ values obtained from the more sophisticated analyses using the Theis, Jacob, or other non-equilibrium approaches. Of course, equilibrium approaches have significant limitations: they cannot be used to determine the aquifer storage coefficient and may lead to large errors in estimating $\mathrm{T}$ where equilibrium conditions have not been reached, or have been achieved due to leaky-aquifer conditions or the occurrence of recharge-boundary effects. Nevertheless, the process of comparing and trying to explain any discrepancies between the $\mathrm{T}$ values derived from equilibrium and non-equilibrium formulae should help to avoid the kind of problems mentioned in the previous paragraph. 
Equilibrium approximations are based on the wellknown Thiem equilibrium equation (1906) which can be written as:

$\mathrm{T}=(2.3 \mathrm{Q} / 2 \pi \mathrm{s}) \log \mathrm{r}_{\mathrm{e}} / \mathrm{r}_{\mathrm{w}}$

where $\mathrm{T}$ is the aquifer transmissivity, $\mathrm{Q}$ the well discharge rate, $s$ the maximum well drawdown, $r_{e}$ the radius of influence of the well, and $r_{w}$ the well radius. A number of simplifications of this formula have been developed, including that described by Logan (1964) (he did not claim the method to be original). The Logan approximation was included in the first edition of the standard reference on pumping-test analysis by Kruseman and de Ridder (1970). However, Logan's method has been omitted from the current (1990) edition of this book, and so it is perhaps less familiar to hydrogeologists nowadays.

In the Thiem equation, the ratio $r_{\mathrm{e}} / \mathrm{r}_{\mathrm{w}}$ cannot be determined accurately unless several observation wells are available during the pumping test. Although this ratio may vary considerably, the log term is relatively insensitive to such variations. Logan (1964) proposed a value of 3.32 as 'typical' for this log ratio, and hence derived the following approximation of the Thiem equation:

$\mathrm{T}=1.22 \mathrm{Q} / \mathrm{s}$.

Similar approximations have been derived elsewhere. For example, the British consultants Hunting Technical Services and Sir M. MacDonald and Partners obtained the relationship $\mathrm{T}=1.32 \mathrm{Q} / \mathrm{s}$ for a large number of well tests on alluvial aquifers in the Indus valley of Pakistan (Bakiewicz et al. 1985).

Strictly speaking, the Logan approximation given above only applies to confined-aquifer conditions. Logan derived the following approximation for the unconfined case:

$\mathrm{T}=2.43 \mathrm{Qb} /(\mathrm{s}(2 \mathrm{~b}-\mathrm{s}))$

where $b$ is the saturated aquifer thickness.

Logan applied his approximation formulae to the results of ten pumping tests taken from the published literature: the transmissivities thus obtained ranged from $+50 \%$ to $-50 \%$ of the published values, with the errors being generally less than $10 \%$. Therefore, the Logan method can give a reasonable first estimate of T, provided that near-equilibrium conditions are achieved when the maximum drawdown is measured.

In addition to analysing specific-capacity data from constant-rate pumping tests, the Logan (or other similar) equilibrium approximation formulae can be applied to step-test data in the form:

$\mathrm{T}=1.22 / \mathrm{B}$

where $\mathrm{B}$ is the formation loss 'constant' obtained from the intercept of the straight line in a plot of s/Q against $\mathrm{Q}$, i.e. B is the specific drawdown value at zero well discharge. This analysis therefore provides an estimate of $\mathrm{T}$ after a correction for well losses. To achieve near-equi- librium conditions, the steps should be continued for as long as practicable. An estimate of T from step tests is especially useful in situations where it is not feasible to carry out long constant-rate tests (Misstear and Beeson 2000).

A further application of this kind of relationship is in the estimation of the required screen length when designing a well. In this case the T term is replaced by $\mathrm{KL}$, where $\mathrm{K}$ is hydraulic conductivity and $\mathrm{L}$ is screen length. A factor of 1.5 or 2 , rather than 1.22 , is normally used to allow for well losses (Clark 1988), giving, for example:

$\mathrm{L}=2 \mathrm{Q} /(\mathrm{sK})$.

Thus, in an extensive aquifer of uniform hydraulic conductivity, the required length of well screen can be estimated for a particular design yield and maximum specified drawdown.

To recap, it is not the intention of this Editor's Message to underrate the importance of carrying out proper pumping-test programmes, or to imply that equilibrium approximation formulae should replace the well-established non-equilibrium analysis methods of Theis, Jacob, and others. The purpose is to highlight the fact that good time-drawdown data are not available in many real-world situations and that even where such data are available, methods involving curve matching or fitting straight lines to time-drawdown plots are sometimes misapplied. Equilibrium approximation methods such as the Logan formula provide a quick and simple means of deriving an initial estimate of transmissivity in both situations.

Keywords editorial $\cdot$ pumping tests $\cdot$ analytical solutions . well performance

\section{References}

Bakiewicz W, Milne DM, Pattle AD (1985) Development of public tubewell designs in Pakistan. Q J Eng Geol 18:63-77

Clark L (1988) The field guide to water wells and boreholes. Geological Society of London Professional Handbook. Wiley, Chichester

Cooper HH, Jacob CE (1946) A generalized graphical method for evaluating formation constants and summarizing well field history. Trans Am Geophys Un 27:526-534

Kruseman GP, de Ridder NA (1970) Analysis and evaluation of pumping test data. Publ 47. ILRI, Wageningen

Kruseman GP, de Ridder NA (1990) Analysis and evaluation of pumping test data, 2nd edn. Publ 47. ILRI, Wageningen

Logan J (1964) Estimating transmissibility from routine production tests of water wells. Ground Water 2:35-37

Misstear BDR, Beeson S (2000) Using operational data to estimate the reliable yields of water-supply wells. Hydrogeol J 8:177-187

Theis CV (1935) The relation between the lowering of the piezometric surface and the rate and duration of discharge of a well using groundwater storage. Trans Am Geophys Union 16:519-524

Thiem G (1906) Hydrologische methoden. Gebhardt, Leipzig 